\title{
Os eventos como estratégia de comunicação nas lutas da cidadania ${ }^{1}$
}

Elaine Cristina Gomes de Moraes²

Murilo Cesar Soares ${ }^{3}$

1 Este artigo foi apresentado no XXXIV Congresso Brasileiro de Ciências da Comunicação realizado em 2011, pela Sociedade Brasileira de Estudos Interdisciplinares da Comunicação.

2 Elaine Cristina Gomes de Moraes é mestranda do programa de pós-graduação em Comunicação Midiática pela Unesp/Bauru. É especialista em Gestão Integrada: Pessoas e Sistemas de Informação pelas Faculdades Integradas de Bauru. Docente das Faculdades Integradas de Bauru. moraes.e@gmail.com

3 Murilo Cesar Soares possui pós-doutorado em Ciência Política pela Universidade Federal de São Carlos, é livre-docente em Sociologia pela Unesp. É docente dos cursos de graduação e pós-graduação em Comunicação pela Unesp/Bauru. murilo@faac.unesp.br 


\section{Resumo}

Este trabalho propõe uma reflexão, sob um olhar diferente, acerca da atividade de eventos. Como instrumento de comunicação dirigida, os eventos são ações planejadas, que visam reunir pessoas com objetivos comuns, para um fim específico, geralmente sob a ótica das organizações. Propõe-se neste estudo um questionamento sobre a relevância dos eventos no contexto dos movimentos sociais, que se mobilizam por meio dessas ações para reivindicar e pressionar o poder público em busca dos direitos da cidadania.

\section{Palavras-chave}

cidadania; comunicação; eventos; movimentos sociais; poder público.

\section{Abstract}

This study proposes some thinking under a different perspective about the Event Organization Activity. As a directed communication instrument, Events are planned actions, aiming at gathering people with common objectives, for a specific goal, usually under the view of organizations. In this study, some questioning on the relevance of Events at the social movement context is proposed, as they organize themselves through these actions in order to claim and pressure the Government for citizenship rights.

\section{Keywords}

citizenship; communication; events; social movements; government. 
Este trabalho integra um projeto em desenvolvimento que propõe uma interface entre os conceitos de eventos, cidadania e movimentos sociais. Pretende-se analisar a relevância dos eventos como formas de representação e visibilidade dos movimentos sociais, que utilizam essas ações como formas de manifestação para pressionar pelos direitos da cidadania. Enquanto os eventos, estratégias de comunicação, são geralmente organizados dentro da perspectiva organizacional, nas mais diversas tipologias como comemorações, lançamentos, divulgações, homenagens e outros, essas ações também são planejadas e realizadas com outros objetivos, por meio de outras tipologias, dentro dos movimentos sociais.

Esses grupos, formados por pessoas que compartilham os mesmos desejos de transformação social, realizam diversas formas de mobilização para pressionar o poder público para que se cumpram os direitos da cidadania, garantidos pela Constituição, os quais não atingem a maioria da população. Nesse sentido, os eventos passam a ser utilizados como formas de representações e ações desses movimentos, por meio de passeatas, marchas, atos públicos, fóruns, assembleias e outros, como meios que conferem visibilidade ao movimento na sociedade civil, imprensa e poder público. Propõe-se neste estudo uma reflexão sobre os eventos em um contexto específico: sua realização como instrumento de comunicação dirigida para promover visibilidade aos movimentos sociais na busca dos direitos da cidadania.

Este estudo compõe-se de uma pesquisa bibliográfica e está dividido em três partes. Inicialmente, faz-se uma breve retomada dos conceitos de cidadania e um resgate do papel dos movimentos sociais na busca desses direitos. Abordase, em seguida, o papel da comunicação nesses movimentos, inicialmente ressaltando-se a importância do compartilhamento de informações e a responsabilidade dos integrantes pelas ações do movimento. Como instrumento de comunicação dirigida, destacam-se os eventos realizados por esses grupos. 
Finalizando, são apresentadas algumas visões conceituais de eventos abordadas na literatura e propõe-se uma reflexão sobre a relevância dessas ações voltadas à proposta deste trabalho.

\section{Cidadania e movimentos sociais}

Muito se fala atualmente sobre cidadania, mas é importante considerar que o termo passou por diversas transformações e tem sofrido algumas distorções. É necessário compreender o seu real significado, o que tem sido feito para a busca dos direitos da cidadania e quais os atores sociais envolvidos nesse processo. Em uma breve retomada histórica, observa-se que o conceito de cidadania foi modificado desde que surgiu na Grécia Antiga, com a manutenção da hierarquização social (OLIVEIRA, 2005), que excluía a participação de mulheres e escravos. Marshall (1967) distinguiu os direitos civis, representados pelo direito de liberdade pessoal, expressão e crença; políticos, como o direito ao voto e ao cargo público; e sociais, expressos pela garantia de um mínimo de bem-estar social e econômico.

Esses conceitos foram ampliados e classificados como direitos de primeira geração, compreendidos pelos direitos civis e políticos, os de segunda geração, que abrangem os direitos sociais, e ainda:

Na segunda metade do nosso século, surgiram os chamados "direitos de terceira geração". Trata-se dos direitos que têm como titular não o indivíduo, mas grupos humanos como o povo, a nação, coletividades étnicas ou a própria humanidade. [...] $\mathrm{Na}$ perspectiva dos "novos movimentos sociais", direitos de terceira geração seriam os relativos aos interesses difusos, como direito ao meio ambiente e direito do consumidor [...]. Já se fala hoje de "direitos de quarta geração", relativos à bioética, para impedir a destruição da vida e regular a criação de novas formas de vida em laboratório pela engenharia genética (VIEIRA, 2009, p. 23). 
Uma abordagem sob a ótica de Gohn (2009) complementa o conceito apresentado por Vieira (2009) ao interpretar a cidadania como um processo coletivo elaborado a partir da organização de grupos por meio de movimentos. Trata-se da cidadania coletiva. Outro ponto destacado pela autora é o papel da educação na acepção de cidadania coletiva, pois ela entende que a cidadania se constrói no processo de luta, que é essencialmente educativo. A cidadania não se constrói por decretos, mas é um processo interno que se estrutura no cotidiano por meio da identidade político-cultural gerada pelas lutas cotidianas.

Também se fala atualmente em cidadania planetária, que surge como contraposição à globalização assimétrica que dificulta o desenvolvimento econômico de países mais pobres. Há também a cidadania empresarial, embora o termo seja considerado controverso, compreendido como o comprometimento das empresas com as questões sociais e com a comunidade (KUNSCH, 2005). Esta autora explica que, devido à importância assumida pelas organizações em uma sociedade globalizada, já não é possível considerar como meta apenas o lucro, excluindo-se como parte do meio no qual atua. Os impactos ambientais e as comunidades locais passaram a ser consideradas como responsabilidade dessas empresas. Por outro lado, esse conceito de cidadania é criticado por alguns autores, que entendem que as organizações são responsáveis por diversos prejuízos às sociedades nas quais atuam e, quando passam a se comprometer com esse meio, obtêm a valorização de seu conceito e suas marcas.

Neste sentido,

As próprias empresas e grupos econômicos que mantêm e aprofundam as distorções que geram todo tipo de carências na população chamam para a sociedade civil (que as inclui) a responsabilidade por diminuir as carências dos grupos desfavorecidos. Mas isso não é encarado como um acerto de contas, e sim uma benesse, uma atitude voluntária e de 'responsabilidade social' que só faz melhorar a imagem das marcas que carregam (CAIRES, 2009, p. 3). 
Observa-se que o conceito de cidadania está ligado diretamente aos direitos e deveres entre o Estado e o cidadão. Portanto, a cidadania relacionase aos "aspectos ligados a justiça, direitos, inclusão social, vida digna para as pessoas, respeito aos outros, coletividade e causa pública no âmbito de um Estado-nação" (KUNSCH, 2005, p. 22). Embora garantidos pela Constituição promulgada em 1988, não se pode negar a falta de acesso a diversos direitos por uma grande parcela da população brasileira. Luca (2003, p. 488) entende que a garantia dos direitos "não basta para torná-los efetivos na prática. As desigualdades sociais deitam raízes profundas na ordem social brasileira e manifestam-se na exclusão de amplos setores". Neste sentido, Peruzzo (2007, p. 46) explica que "a cidadania é histórica e, portanto [...] o grau de direitos alcançados depende da capacidade de articulação civil e da correlação de forças no embate político".

Com o objetivo de lutar pela prática efetiva dos direitos da cidadania, surgem os movimentos sociais, que atuam por meio de ações de mobilização de grupos formados por pessoas com os mesmos propósitos para transformar determinadas necessidades em realidade. O papel dos movimentos sociais está relacionado ao conceito de cidadania na medida em que a conquista dos direitos

depende do enfrentamento político adotado por quem tem pouco poder. Só existe cidadania se houver a prática da reivindicação, da apropriação de espaços, da pugna para fazer valer os direitos do cidadão (MANZINICOVRE, 1991, p. 10).

Os movimentos sociais tiveram uma atuação significativa nas décadas de 70 e 80 , quando surgiram em oposição às mais de duas décadas de ditadura militar. Esses movimentos são 
como as antigas análises conservadoras escritas nos manuais antigos, ou como ainda são tratados na atualidade por políticos tradicionais (GOHN, 2003, p. 189).

Esses movimentos são compreendidos como agrupamentos "coletivos francamente organizados que atuam juntos de maneira não-institucionalizada para produzir uma mudança na sociedade" (SZTOMPKA apud KUNSCH, 2007, p. 61). Como o Brasil passou por diversos cenários socioeconômicos desde o retorno da democracia até o processo de globalização, esses movimentos também vivenciaram uma etapa de transformação estrutural, a qual significou, para alguns atores, perda de visibilidade, enfraquecimento e até mesmo decadência. A crise aconteceu, na visão de Gohn (2009), porque, após a Constituição de 1988, muitos líderes passaram a atuar em partidos políticos, a igreja passou a agir de maneira menos contestatória, em virtude de pressões do Vaticano, e algumas verbas internacionais de fomento aos movimentos da América Latina foram transferidas para o Leste Europeu.

Essa mesma visão é compartilhada por César (2007) ao mencionar o prejuízo nessa mudança de identidade, pois, embora os movimentos sociais tenham passado por um processo de profissionalização, muitos se articulam por meio de projetos, o que pode causar um engessamento nas demandas e deixá-los numa situação de passividade diante de seus agentes. Por outro lado, há uma outra interpretação para essa transformação vivenciada pelos movimentos sociais ao se mencionar que

Os movimentos populares procuram adquirir mais competência para poderem participar mais efetivamente discutindo projetos, pressionando e, possivelmente, se preparando para passarem a propor projetos, ou seja, buscam adquirir competência para melhor negociar com o Poder Público, para melhor interferir no processo de construção da realidade (PERUZZO, 1993, p. 4). 
Dessa forma, esse período de reestruturação dos movimentos pode ser interpretado como consequência das transformações políticas e socioeconômicas que o país vivenciou. Se na década de 70, com a presença de um governo militar autoritário, os movimentos tinham mais visibilidade por meio de suas ações reivindicatórias, a partir da década de 90, passam por uma reestruturação.

Retomando a visão de Manzini-Covre (1991), os direitos da cidadania, embora assegurados pela lei, tornam-se efetivos na prática apenas por meio da reivindicação. Portanto, seria uma visão ingênua afirmar que, após esse período de reestruturação, os movimentos sociais foram extintos. Surgiram outras estruturas sociais geridas no âmbito dos movimentos sociais: núcleos de socialização, como clubes de mães; núcleos econômicos, representados por associações de produtores; núcleos políticos, por meio de associações de bairro; núcleos culturais, como movimento negro (CASTRO ALVES (sd) apud PERUZZO, 1993).

A partir desse momento em que as pessoas passam a usufruir de liberdade para formar grupos com os mesmos interesses, a população começa a atuar de forma mais direta por meio de associações em bairros e municípios. Essas organizações são administradas por diretorias eleitas democraticamente e contam com a participação da população para discutir, propor, decidir e ajudar a executar. As associações, representando as necessidades da população, passam a se relacionar de forma direta com o poder público (PERUZZO, 1993). Se, por um lado, as formas de manifestação sofreram um processo de transformação, há que se considerar que as razões que levavam as pessoas às ruas para as reivindicações ainda se encontram presentes nas novas formas de organização desses grupos. Neste sentido, o papel da comunicação torna-se um elemento indispensável para produzir visibilidade aos movimentos. 


\section{O papel da comunicação na mobilização social e os direitos da cidadania}

A comunicação assume papel estratégico no contexto dos movimentos sociais. Trata-se do meio para torná-los não apenas reconhecidos como de promover-lhes a visibilidade. Muito além de instrumento para a divulgação de ações, ideias e projetos, a comunicação requer um planejamento que possibilite o envolvimento das pessoas e desperte o sentimento de responsabilidade pelo projeto. Compreendida como comunicação popular no âmbito dos movimentos sociais, Peruzzo (2008) explica que a comunicação comunitária é um processo de comunicação que se constitui no âmbito dos movimentos populares e comunidades diversas, ligadas por uma base geográfica ou outras afinidades. Trata-se, portanto, de um canal de comunicação do cidadão, sem fins lucrativos, que participa de forma ativa horizontal, com caráter educativo, cultural e mobilizatório.

A relevância desse processo de comunicação é salientada por Yamamoto (2009, p. 27), ao afirmar que ela "enfatiza o exercício da cidadania a partir de ações políticas que incluem desde a consciência do sujeito individual diluído num todo social, à práxis comunicativa que se firma no pressuposto da participação coletiva". Um processo de mobilização social é compreendido como a convocação de vontades para atuar num objetivo comum, porém, trata-se de uma opção: as pessoas são chamadas, mas participar ou não é uma decisão de cada um, pois a participação é um ato de liberdade (TORO \& WERNECK, 2007). Esses autores entendem que a mobilização social é um ato de comunicação, não se restringindo à propaganda e às divulgações de suas propostas, embora a divulgação seja necessária, mas como um processo de compartilhamento de discurso, visões e informações. Neste sentido, observa-se o papel da comunicação como um importante instrumento de coletivização, pois 
feito e decidido por outros, em seus próprios campos de atuação, com os mesmos propósitos e sentidos (TORO \& WERNECK, 2007, p. 14).

Encontra respaldo nessa visão a relação entre o processo de coletivização e a comunicação, na medida em que o tornar coletivo requer a circulação de informações, que visam não apenas divulgar, mas promover o compromisso com os resultados. A comunicação assume um papel específico nos projetos de mobilização social a fim de dinamizar e potencializar os movimentos, pois

Sendo a participação uma condição intrínseca e essencial para a mobilização, a principal função da comunicação em um projeto de mobilização é gerar e manter vínculos entre os movimentos e seus públicos, por meio do reconhecimento da existência e importância de cada um e do compartilhamento de sentidos e valores (HENRIQUES et al., 2007, p. 20-21).

É fundamental que um projeto de mobilização social contemple o desenvolvimento de ações que estimulem a cooperação e os participantes se sintam realmente envolvidos e responsáveis pelo projeto, caso contrário, não se poderia considerar a existência de um projeto de mobilização, mas uma sequência isolada de ações. Neste sentido, há um grande desafio para a comunicação no contexto da mobilização, pois esta deve "tocar a emoção das pessoas, sem, contudo, manipulá-las, porque, se assim for feito, ela será autoritária e imposta" (HENRIQUES et al., 2007, p. 37).

É necessário despertar o sentimento de co-responsabilidade entre os participantes. Esses mesmos autores explicam que em um projeto de mobilização social há diversas formas de vínculos com o grupo. Elas envolvem: localização espacial; informação, de acordo com o nível das informações recebidas; julgamento, quando gera uma tomada de posição; ação, geração de idéias e contribuições; coesão, quando as ações do público são interdepentendes; continuidade, as ações são permanentes; co-responsabilidade, as pessoas se 
sentem responsáveis pelo sucesso do projeto; e participação institucional, que se concretiza em um nível contratual.

A relevância da comunicação encontra-se presente na formação desses vínculos desde a utilização de instrumentos como a publicidade e a divulgação de informações, às ações estratégicas como requisitos para proporcionar visibilidade ao movimento. Henriques et al. (2007) explicam que os movimentos sociais não lutam por reconhecimento, mas por visibilidade. Neste contexto, argumentam que

A busca pela visibilidade vem em função da necessidade de que as reivindicações e preocupações dos indivíduos tenham um reconhecimento público, servindo de apelo à mobilização dos que não compartilham o mesmo contexto espaço/temporal (HENRIQUES et al., 2007, p. 18).

No que tange à questão da visibilidade, vale refletir sobre as formas de comunicação que podem ser utilizadas para esse fim. Por um lado, observa-se que o processo de mobilização inicia-se a partir do envolvimento dos atores sociais diretamente relacionados aos objetivos do movimento. Salientam essa visão Toro \& Werneck (2007) quando explicam que a meta do projeto de comunicação de um processo de mobilização deve ser "o compartilhamento, o mais abrangente possível, de todas as informações [...] até as ações que estão sendo desenvolvidas em outros lugares, por outras pessoas, o que pensam os diversos segmentos da sociedade" (TORO \& WERNECK, 2007, p. 67).

Por outro lado, a partir da mobilização formada por aqueles que representam o grupo em busca de um propósito de transformação social, faz-se necessário o processo de visibilidade do movimento, função que pode ser realizada pelos meios de comunicação. Diante dessa realidade, um ponto pertinente a se considerar é a utilização dos veículos de comunicação dirigida nesses movimentos para promover visibilidade, compreendidos como instrumentos por meio dos quais 
se transmite determinada mensagem a um público específico e permitem um feedback mais rápido (FERREIRA, 2006).

Neste estudo, propõe-se uma análise do que esse autor chama de veículos aproximativos, como sendo "aqueles que permitem qualquer aproximação física ou virtual entre os públicos e a instituição" (FERREIRA, 2006, p. 94), compreendidos como eventos. Neste caso, as instituições são representadas pelos movimentos sociais e os eventos são explicados como as diversas formas de ações para promover sua aproximação com seu público de interesse. Os eventos são realizados sob a forma de diversas tipologias: reuniões, atos públicos, fóruns, passeatas, marchas, assembleias, abaixo-assinados, etc. Essas ações são geralmente realizadas no ambiente corporativo, com o objetivo de aproximar uma organização de seus públicos, com a finalidade de criar ou fortalecer sua imagem ou seus produtos, visando lucros. No contexto dos movimentos sociais, os eventos são praticados como forma de sensibilizar a opinião pública, a imprensa e o poder público para as questões pelas quais estão se mobilizando. A questão proposta para análise no presente estudo é, pois, o papel dos eventos enquanto formas de representação dos movimentos sociais. Faz-se necessário, inicialmente, recorrer às abordagens teóricas de alguns autores que se dedicam ao estudo de eventos.

\section{Eventos}

O conceito de evento é amplo, porém, não há um consenso entre os autores que o abordam. Diferentes aspectos são enfatizados por esses autores. Cesca (2008) e Bettega (2006) ressaltam o evento como fato que desperta atenção e, portanto, pode virar notícia. Aspectos como acontecimento especial, de sucesso, planejado são abordados por Britto \& Fontes (2002). Sob uma ótica organizacional, o evento compõe "uma economia de mercado, ora visando diretamente ao lucro para o empreendedor, ora visando à obtenção de outros graus de lucro indireto" (ANDRADE, 2007, p. 99). 
Meirelles (1999, p. 22) o classifica como "um dos mais ricos recursos da comunicação, pois reúne, ao mesmo tempo, a comunicação oral, escrita, auxiliar e aproximativa". É um veículo aproximativo, na medida em que mantém a compreensão mútua entre os interessados, com apoio de outros veículos escritos, orais, mais diretos e econômicos (BRITTO \& FONTES, 2002). Kunsch (1986, p. 102) o classifica como "um excelente meio de comunicação dirigida aproximativa". A autora ressalta a relevância dessa ação quando explica que "a importância da realização de um evento está, sobretudo, no aproveitamento do instante, do ambiente ou da presença de pessoas, pois dessa atitude resulta a impressão final" (KUNSCH, 1986, p. 102).

Ainda como um instrumento de comunicação dirigida, o evento é compreendido como

\begin{abstract}
um acontecimento excepcional previamente planejado, que ocorre em determinado tempo e local e gera grande envolvimento e mobilização de um grupo ou comunidade, buscando a integração, a difusão e a sensibilização entre os participantes para os objetivos pretendidos. Estes devem ser colocados de forma clara e explícita, para que o público-alvo receba e assimile os temas abordados e as ações desenvolvidas durante os eventos (HAMAM, 2011, p. 130).
\end{abstract}

Em uma breve análise sobre os conceitos desses autores, pode-se entender que o evento é uma atividade de comunicação dirigida, minuciosamente planejada, não rotineira, em data e local específico, com a participação de pessoas com objetivos em comum. Essas visões apresentadas sob diferentes vieses permitem uma reflexão sobre a relevância dos eventos enquanto veículo de comunicação dirigida. Alguns leigos enfocam o caráter festivo como parte intrínseca dessas ações, com o objetivo de provocar emoções no público envolvido. É importante, no entanto, tomar um cuidado para não reduzir essas ações à realização de festas, que exigem planejamento complexo e têm como uma das funções transmitir uma mensagem ao público de interesse. Não se pretende aqui minimizar os esforços necessários para a realização de uma festa, 
porém, convém lembrar que essa atividade refere-se a apenas um dos tipos de eventos. É importante ressaltar que essas ações podem ser realizadas em diversos formatos, condizentes com os objetivos a que se propõem. Alguns tipos de eventos são comuns, como: palestra, congresso, comemoração, lançamento, posse, inauguração, feira, exposição, entre outros.

Observa-se, por outro lado, algumas ações praticadas por movimentos sociais, que os representam e promovem visibilidade às lutas e reivindicações. Os movimentos "adotam diferentes estratégias que variam da simples denúncia, passando pela pressão direta (mobilizações, marchas, concentrações, passeatas, distúrbios à ordem constituída, atos de desobediência civil, negociações etc.), até as pressões indiretas" (GOHN, 2007, p. 13). Retomando os conceitos apresentados anteriormente, essas ações, com objetivo de mobilização, são concebidas como eventos, por se tratar de atividades planejadas, embora sem necessariamente possuírem o caráter profissional presente no contexto organizacional. Nos movimentos sociais, o objetivo é dar visibilidade, perante autoridades e opinião pública das lutas por direitos existentes e não efetivamente desfrutados, ou seja, a busca pelos direitos da cidadania.

A literatura pesquisada sobre eventos não contempla essa atividade como forma de representação dos movimentos sociais, tampouco as tipologias utilizadas especificamente por esses grupos. A importância da realização de eventos é ressaltada principalmente como forma de criar ou firmar a imagem de quem os promove. Os eventos para a cidadania, classificados como "beneficentes", não são abordados com frequência pelos autores da área. Britto \& Fontes (2002, p. 134) explicam que "esses eventos refletem programas e ações sociais que são divulgados e/ou auxiliados em acontecimentos públicos". Eventos como passeatas e marchas não são mencionados. Já atividades comuns também aos segmentos organizacional e acadêmico, como fórum, assembleia, reunião, debate, seminário e outros, são explanados pelos autores. 
Os eventos realizados no contexto dos movimentos sociais representam a vontade coletiva. Com uma logística peculiar, na qual os atores sociais envolvidos costumam participar de forma ativa nas diversas etapas do processo, essas ações contribuem para dar visibilidade desses movimentos, na medida em que expressam suas reivindicações e pressionam o poder público. Além disso, esses eventos costumam contar com a presença da imprensa. Esta é buscada pelos movimentos sociais, pois tem a capacidade de amplificar a expressão dos eventos e do próprio movimento, ao difundi-los para audiências massivas, nacionais ou internacionais, tornando as reivindicações conhecidas e legitimando-as. As pessoas são chamadas a participar dessas ações e o caráter emocional adquire grande relevância, pois "os atores sociais podem se sensibilizar e se identificar com a beleza e coerência das peças gráficas do projeto, com o ritual das reuniões e eventos que promove, com os valores que defende, com os conhecimentos que dissemina" (HENRIQUES et al., 2007, p. 24).

Por outro lado, é importante destacar a visão de Toro \& Werneck (2007) de que a participação em um evento não é suficiente para considerar a existência de uma mobilização social. Um dos elementos que caracterizam um evento, a não realização no cotidiano, demonstra, para esses autores, que a realização de eventos não é suficiente para mobilizar, mesmo em se tratando de um conjunto dessas ações. O evento tem dois sentidos no processo de mobilização:

\footnotetext{
Enquanto momento de troca e difusão de informações. Enquanto "liturgia", isto é, como uma verificação pública, através de símbolos, onde manifestamos nossas crenças. Esse é um papel muito relevante, especialmente no início do processo e em certos momentos de seu desenrolar em que é preciso "renovar a nossa fé", revitalizar nossos sentimentos e disposições (TORO \& WERNECK, 2007, p. 89).
}

Ainda no entendimento desses autores, ações como campanhas são importantes como partes do processo de mobilização, pois são formas de incentivo às pessoas. Porém, há uma divergência em virtude do caráter atemporal da mobilização, enquanto as campanhas possuem início, meio e fim. 


\section{Considerações finais}

Como definido anteriormente, este trabalho teve como objetivo propor uma reflexão, à luz da bibliografia. Em uma breve retomada histórica abordou-se que a cidadania é um direito para todos, embora alguns direitos sejam restritos, na prática, a apenas uma parcela da população. Por meio de mobilizações, os movimentos sociais pressionam por esses direitos e lutam por visibilidade. Ressalta-se o papel da comunicação para que a mobilização efetivamente aconteça. É necessário divulgar informações, convocar pessoas e despertar o sentimento de co-responsabilidade para que os integrantes do grupo entendam a importância de seus atos para com as propostas do movimento. É importante também promover a visibilidade do movimento, junto à opinião pública, a fim de obter respaldo social às reivindicações, de modo a pressionar autoridades e o Estado a encaminharem soluções para os problemas.

Procurou-se enfatizar a relevância dos eventos, enquanto instrumentos de comunicação dirigida e formas de representações dos movimentos sociais, que Ihe proporcionam visibilidade e, consequentemente, contribuem com os objetivos desses movimentos. Os eventos, como ações planejadas, realizados cada vez mais por organizações que visam promover, divulgar ou vender imagem ou produto, não recebem o mesmo destaque dos pesquisadores quando realizados com fins não lucrativos, pelos movimentos sociais. Na literatura pesquisada, apenas um autor mencionou os eventos beneficentes e nenhum mencionou a realização de eventos como ações que podem ter um objetivo voltado aos cidadãos. Em uma sociedade democrática, com grandes desigualdades sociais, a cidadania é um objetivo ainda a ser alcançado pela maioria da população e os eventos podem contribuir com esse propósito. Portanto, pelas elaborações teóricas apresentadas, conclui-se que os eventos, apesar de serem importantes instrumentos de comunicação dirigida, ainda não foram profundamente estudados como meios de representação e de dar visibilidade dos movimentos sociais. 


\section{Referências}

ANDRADE, R. B. Manual de eventos. Caxias do Sul: Educs, 2007.

BETTEGA, M. L. Eventos e cerimonial: simplificando ações. Caxias do Sul: Educs, 2006.

BRITTO, J.; FONTES, N. Estratégias para eventos: uma ótica do marketing e do turismo. São Paulo: Aleph, 2002.

CAIRES, L. "Cidadania, movimentos sociais e comunicação alternativa pela internet: algumas questões na perspectiva do centro de mídia independente Brasil". Revista Alterjor, São Paulo, v. 1, n. 00, ago-dez. 2009. Disponível em: http://www.usp.br/ alterjor/Caires_CMIB.pdf. Acesso em: 15 abr. 2011.

CÉSAR, R. E. "Movimentos sociais, comunidade e cidadania". In: KUNSCH, M. M. K.; KUNSCH, W. L. (Org.). Relações públicas comunitárias: a comunicação em uma perspectiva dialógica e transformadora. São Paulo: Summus, 2007.

CESCA, C G. G. Organização de eventos: manual para planejamento e execução. São Paulo: Summus, 2008.

FERREIRA, W. "Comunicação dirigida: instrumento de relações públicas". In: KUNSCH, M. M. K. (Org.). Obtendo resultados com relações públicas. São Paulo: Cengage Learning, 2011.

GOHN, M. G. "Cidadania, meios de comunicação de massas, associativismo e movimentos sociais". In: PERUZZO, C. M. K.; ALMEIDA, F. F. (Org.). Comunicação para a cidadania. São Paulo: INTERCOM; Salvador: UNEB, 2003.

. Movimentos sociais no início do século XXI. Rio de Janeiro: Vozes, 2007. . Movimentos sociais e educação. São Paulo: Cortez, 2009.

HAMAM, R. "O evento integrando o mix da comunicação". In: KUNSCH, M. K. (Org.). Obtendo resultados com relações públicas. São Paulo: Cengage Learning, 2011.

HENRIQUES, M. S. et al. Comunicação e estratégias de mobilização social. Belo Horizonte: Autêntica, 2007. 
KUNSCH, M. K. Planejamento de relações públicas na comunicação integrada. São Paulo: Summus, 1986.

. "Campos de estudos emergentes em comunicação nas novas cidadanias". In: BEZZON, L. C. (Org.). Comunicação, política e sociedade. São Paulo: Alínea, 2005. LUCA, T. R. "Direitos sociais no Brasil". In: PINSKY, J.; PINSKY, C. B. (Org.). História da cidadania. São Paulo: Contexto, 2003.

MANZINI COVRE, M. O que é cidadania. São Paulo: Brasiliense, 1991.

MARSHALL, T. H. Cidadania, classe social e status. Rio de Janeiro: Zahar, 1967.

MEIRELLES, G. F. Tudo sobre eventos. São Paulo: STS, 1999.

OLIVEIRA, M. C. "Panorama social e cidadania: uma análise sobre o Brasil na ótica da comunicação". In: BEZZON, Lara Crivelaro (Org.). Comunicação, política e sociedade. São Paulo: Alínea, 2005.

PERUZZO, C. K. "Relações públicas, movimentos populares e transformação social". Revista Brasileira de Comunicação, v. XVI, n. 2. São Paulo: Intercom - Sociedade Brasileira de Estudos Interdisciplinares da Comunicação, 1993. Disponível em: http:// www.bocc.ubi.pt/pag/peruzzo-cicilia-relacoes-publicas.pdf. Acesso em: 10 mar. 2011.

. "Comunicação para a cidadania ativa". In: KUNSCH, M. K.; KUNSCH, W. L. (Org.). Relações públicas comunitárias: a comunicação em uma perspectiva dialógica e transformadora. São Paulo: Summus, 2007.

Aproximações entre comunicação popular e comunitária e a imprensa alternativa no Brasil na era do ciberespaço. Disponível em: http://www.intercom.org. br/papers/nacionais/2008/resumos/R3-0716-1.pdf. Acesso em: 25 maio 2011.

TORO, J. B.; WERNECK, N. M. D. Mobilização social: um modo de construir a democracia e a participação. Belo Horizonte: Autêntica, 2007.

VIEIRA, L. Cidadania e globalização. Rio de Janeiro: Record, 2009.

YAMAMOTO, E. Y. "Comunicação popular e cidadania". In: VICENTE, M. M. (Org.). Comunicação e cidadania. Bauru: Edusc, 2009. 